\title{
Segmentation of Worked Examples: Effects on Cognitive Load and Learning
}

Citation for published version (APA):

Spanjers, I. A. E., Van Gog, T., \& Van Merrienboer, J. J. G. (2012). Segmentation of Worked Examples: Effects on Cognitive Load and Learning. Applied Cognitive Psychology, 26(3), 352-358.

https://doi.org/10.1002/acp.1832

Document status and date:

Published: 01/01/2012

DOI:

10.1002/acp.1832

Document Version:

Publisher's PDF, also known as Version of record

Document license:

Taverne

Please check the document version of this publication:

- A submitted manuscript is the version of the article upon submission and before peer-review. There can be important differences between the submitted version and the official published version of record.

People interested in the research are advised to contact the author for the final version of the publication, or visit the DOI to the publisher's website.

- The final author version and the galley proof are versions of the publication after peer review.

- The final published version features the final layout of the paper including the volume, issue and page numbers.

Link to publication

\footnotetext{
General rights rights.

- You may freely distribute the URL identifying the publication in the public portal. please follow below link for the End User Agreement:

www.umlib.nl/taverne-license

Take down policy

If you believe that this document breaches copyright please contact us at:

repository@maastrichtuniversity.nl

providing details and we will investigate your claim.
}

Copyright and moral rights for the publications made accessible in the public portal are retained by the authors and/or other copyright owners and it is a condition of accessing publications that users recognise and abide by the legal requirements associated with these

- Users may download and print one copy of any publication from the public portal for the purpose of private study or research.

- You may not further distribute the material or use it for any profit-making activity or commercial gain

If the publication is distributed under the terms of Article $25 \mathrm{fa}$ of the Dutch Copyright Act, indicated by the "Taverne" license above, 


\title{
Segmentation of Worked Examples: Effects on Cognitive Load and Learning
}

\author{
INGRID A. E. SPANJERS ${ }^{1}$ *, TAMARA VAN GOG ${ }^{2}$ and JEROEN J. G. VAN MERRIËNBOER ${ }^{1}$ \\ ${ }^{1}$ Department of Educational Development and Research and School of Health Professions Education, Maastricht University, The Netherlands \\ ${ }^{2}$ Institute of Psychology, Erasmus University Rotterdam, The Netherlands
}

\begin{abstract}
Summary: Two ways to improve worked examples are investigated: presenting them in a segmented format (i.e., in pieces separated by blank lines) and instructing students to segment them actively (i.e., students must divide the examples in pieces). Segmented examples are expected to support learning because they show which information elements belong together. Learners might also be encouraged to think about which information elements belong together when they are instructed to actively segment, but on the negative side, this is an additional task that might impose extra cognitive load without facilitating learning. Results showed that students in the actively segmenting condition invested more effort in learning than students in the other conditions without performing better. Furthermore, studying segmented examples required less effort to achieve equal learning outcomes than studying nonsegmented ones. So, presenting learners with segmented examples improved the efficiency of the learning process, whereas instructing them to actively segment decreased this efficiency. Copyright (C) 2011 John Wiley \& Sons, Ltd.
\end{abstract}

A large body of research has shown that for low prior knowledge learners, instruction consisting of studying worked examples is more effective (i.e., higher learning outcomes) and efficient (i.e., equal/higher learning outcomes reached with less/equal investment of time and/or mental effort) than instruction consisting of problem solving (for reviews, see Atkinson, Derry, Renkl, \& Wortham, 2000; Sweller, Van Merriënboer, \& Paas, 1998) or tutored problem solving (McLaren, Lim, \& Koedinger, 2008; Schwonke et al., 2009). In addition to studying the benefits of worked examples compared with problem solving and tutored problem solving, research has also investigated means to further improve learning from worked examples by improving the example design (for reviews, see Atkinson et al., 2000; Paas \& Van Gog, 2006; Van Gog \& Rummel, 2010) and/or adding interactivity (Atkinson \& Renkl, 2007). The present study investigates the effects of segmentation, both as an example design characteristic and as a form of interactivity, on learning outcomes and mental effort and their combination.

\section{Learning from worked examples}

Instruction consisting of problem solving presents students only with a description of some 'givens' (e.g., how much faster a car is driving than a truck and the time it takes the car to overtake a truck) and a goal statement (e.g., calculate how fast each vehicle is traveling; see Cooper \& Sweller, 1987). Because they lack knowledge of the procedures required to solve such problems, instruction consisting of problem solving forces low prior knowledge learners to resort to the so-called 'weak strategies', such as trial-and-error or means-ends analysis, to try to achieve the goal state. Through the use of weak strategies, a learner may eventually find the solution to the problem. However, such strategies impose a high cognitive load (i.e., they draw heavily on working memory resources) and do not facilitate the construction of a cognitive schema of how such problems should be solved. In other words, although such strategies may sometimes lead to acceptable performance, they do not lead to effective and

*Correspondence to: Ingrid A. E. Spanjers, Department of Educational Development and Research, Maastricht University, PO Box 616, 6200 MD Maastricht, The Netherlands.

E-mail: i.spanjers@maastrichtuniversity.nl efficient learning as shown by the ability to perform similar tasks in the future (Sweller, 1988; Sweller et al., 1998).

Worked examples provide the learner with the givens and a goal statement as well as with the solution moves that should be taken successively to solve the problem and achieve the goal state. Consequently, the high load imposed by weak problemsolving strategies that do not contribute to learning is prevented, and learners can devote the available working memory capacity to studying the given solution moves and constructing a cognitive schema that guides future problem solving (Sweller et al., 1998). Therefore, compared with instruction consisting of problem solving, instruction that relies more heavily on studying worked examples reduces extraneous (i.e., ineffective) cognitive load on working memory and enhances learning as well as transfer performance. That is, students not only learn how to solve identical problems but also novel problems for which they have to flexibly adapt the learned solution procedure (see Sweller et al., 1998). In addition to enhanced learning and transfer test performance, a heavier reliance on worked examples has also been shown to result in lower acquisition time (Sweller \& Cooper, 1985; Van Gog, Paas, \& Van Merriënboer, 2006; Zhu \& Simon, 1987), lower cognitive load experienced by students during instruction (Paas \& Van Merriënboer, 1994; Van Gog et al., 2006), and lower cognitive load experienced by students during the test (Paas, 1992; Paas \& Van Merriënboer, 1994).

This has become known as 'the worked example effect' (Sweller et al., 1998; Sweller, 2006). It should be noted though that these beneficial effects of worked examples on learning outcomes, acquisition time, and cognitive load, compared with problem solving, seem to apply primarily to low prior knowledge learners: for advanced learners who have more prior knowledge of the problem-solving procedure, worked examples may no longer be effective or may even hamper learning (Kalyuga, Chandler, Tuovinen, \& Sweller, 2001; this is an example of the 'expertise reversal effect', see Kalyuga, 2007; Kalyuga, Ayres, Chandler, \& Sweller, 2003). Moreover, these beneficial effects apply only when the examples are well designed. That is, following early studies on the effects of worked examples compared with problem solving by Sweller and Cooper (1985) and Cooper and Sweller (1987), it was soon discovered that 
studying worked examples was not always more effective for learning than problem solving. Rather, the design of the examples played a crucial role in their effectiveness (Tarmizi \& Sweller, 1988). If worked examples induced split attention, by presenting mutually referring information sources such as text and picture/diagram separately rather than integrated, a worked example effect was not obtained (Tarmizi $\&$ Sweller, 1988). On the other hand, when information sources are not mutually referring and can be easily understood in isolation, extraneous cognitive load is imposed by the need to process redundant information. In this case, one of the information sources should be left out (see Chandler $\&$ Sweller, 1991). The preventions of split attention and redundancy are by now regarded as basic design guidelines for worked examples.

Next to these basic design guidelines, the effectiveness of examples can be enhanced even further by improving their design to cue important aspects of the procedure and/or stimulate more active processing of the examples (for reviews, see Atkinson et al., 2000; Paas \& Van Gog, 2006; Van Gog \& Rummel, 2010). Examples of guidelines aimed at the further improvement of worked examples are providing instructional explanations (e.g., Lovett, 1992), providing process information that helps students understand the principles behind the solution moves (e.g., Van Gog, Paas, \& Van Merriënboer, 2008), asking students to complete moves in partially worked-out examples (e.g., Paas, 1992; Van Merriënboer, 1990; Van Merriënboer \& De Croock, 1992), and asking students to self-explain worked-out solution moves (e.g., Atkinson, Renkl, \& Merrill, 2003). The present study focuses on effects of segmentation.

\section{Effects of segmentation on cognitive load and learning outcomes}

Effects of segmentation have mainly been studied in research on dynamic visualizations, where segmentation refers to presenting an animation or video not as a continuous stream of information but divided into meaningful pieces. Segmentation has been proposed as a means to improve the effectiveness of dynamic visualizations (e.g., Ayres \& Paas, 2007b; Mayer \& Moreno, 2003; Moreno \& Mayer, 2007; Wouters, Paas, \& Van Merriënboer, 2008). A number of studies indeed found positive effects of segmentation of dynamic visualizations (e.g., Hasler, Kersten, \& Sweller, 2007; Mayer \& Chandler, 2001; Moreno, 2007; Spanjers, Wouters, Van Gog, \& Van Merriënboer, 2011). For example, Mayer and Chandler (2001) found that students were better able to solve transfer questions (i.e., questions measuring understanding of the material rather than reproduction) after having seen a segmented animation than a nonsegmented animation. A recent study with animated worked examples (animations demonstrating and explaining how to solve a problem) on probability calculation has shown that for low prior knowledge learners, segmentation may reduce cognitive load (as measured by mental effort investment, see Paas, 1992), leading to higher efficiency of learning processes (for a discussion of efficiency, see Hoffman \& Schraw, 2010; Paas \& Van Merriënboer, 1993; Van Gog \& Paas, 2008): the same level of test performance was reached by low prior knowledge learners with less investment of mental effort in studying the animations (Spanjers et al., 2011).

Two explanations have been offered for the beneficial effects of segmentation of dynamic visualizations on cognitive load and learning outcomes (Spanjers, Van Gog, \& Van Merriënboer, 2010). First, in the studies on segmentation conducted so far, segmentation was associated with pauses between segments. The information in dynamic visualizations is often transient, that is, presented information quickly disappears and is continuously replaced by new information. To deal with this transience, learners have to perform cognitive activities imposing extraneous cognitive load (Leahy \& Sweller, 2011), that is, they have to maintain information in working memory to link it to later presented information while simultaneously processing new information (e.g., Ayres \& Paas, 2007a; Lowe, 1999; Mayer $\&$ Moreno, 2003). When the dynamic visualization has a complex content (i.e., causes a high intrinsic cognitive load), the consequence of this extraneous cognitive load may be that learners are not able to perform all the necessary cognitive processes, and information is lost before it can be integrated with other information and prior knowledge (Mayer \& Moreno, 2003). Consequently, the transience of dynamic visualizations may hinder learning, especially when the content of the dynamic visualizations is complex (Ayres \& Paas, 2007a; Leahy \& Sweller, 2011). Thus, the pauses between segment may have caused the beneficial effects on cognitive load and learning outcomes because they give students time to perform the cognitive activities needed for learning on smaller units of information, without having to simultaneously attend to the next unit of information (e.g., Mayer \& Moreno, 2003; Moreno, 2007; Moreno \& Mayer, 2007).

Second, segmentation breaks dynamic visualizations down into meaningful pieces. People mentally divide events or procedures described in text or shown in dynamic visualizations into pieces (e.g., Kurby \& Zacks, 2008; Zacks, Speer, \& Reynolds, 2009; Zacks, Speer, Swallow, Braver, \& Reynolds, 2007), and this influences the way in which they remember the information (see Kurby \& Zacks, 2008; Zacks et al., 2007). Providing learners with instructional material that is already divided into pieces may reduce cognitive load because the segments provide a cue, so learners do not have to search for the boundaries between pieces themselves (cf. Schwan, Garsoffky, \& Hesse, 2000; see also Wouters et al., 2008). This reduction in cognitive load may lead to an increase in learning outcomes.

Although transience is a factor hindering learning from complex dynamic visualizations (Ayres \& Paas, 2007a; Leahy \& Sweller, 2011), transience does not play a role in 'traditional' written instructional material and worked examples. Yet, studies by Catrambone (1995) and Florax and Ploetzner (2010) suggest that segmentation can also be applied to written text and written worked examples. Florax and Ploetzner (2010) examined whether the split-attention effect in learning from text and pictures is a result of physical integration (i.e., reduction in spatial distance) or of the usually associated labeling of the picture and segmentation of the text to accomplish such physical integration. They found a significant effect on learning outcomes only of segmentation. Catrambone (1995) showed that making subgoals 
explicit in worked examples by visually isolating a move in the solution procedure (through placing it on a separate line) fostered learning. These findings support the 'cueing' explanation for the effectiveness of segmentation provided by Spanjers et al. (2010). According to Catrambone's subgoal learning model (1996, 1998), a cue as to which information elements belong together stimulates learners to group those elements and may induce learners to self-explain why they belong together, which fosters learning. Both of these studies did not measure effects of segmentation of worked examples or text on cognitive load, however.

\section{This study}

As discussed before, Spanjers et al. (2011) found that studying segmented animated worked examples led to equal learning outcomes with lower investment of effort. The current study will use written worked examples consisting of the same texts as used in the animations by Spanjers et al. (though in written rather than spoken form) to investigate whether cueing indeed contributed to this finding. Though it is plausible that learners pause shortly at the end of a segment, written worked examples are not transient and pauses can be made at any time during reading; hence, the 'pausing explanation' would be an unlikely explanation for finding positive results, and positive effects of segmentation in this study would provide evidence for the plausibility of the 'cueing explanation' of the segmentation effect.

In addition, it will be investigated whether instructing students to actively segment the written examples (i.e., dividing the examples in pieces themselves) while studying the material improves their learning outcomes. On one hand, interactivity has been proposed as a means to stimulate learners to more actively process examples (Atkinson \& Renkl, 2007). Instructing learners to actively segment instructional material may focus their attention on subgoals, just like segmented examples do. It may also encourage learners to process the examples even more deeply because they have to decide for themselves which information elements belong together. This may increase cognitive load during learning and support learning as well if the additional load is associated with activities that directly contribute to learning (i.e., germane load; Sweller et al., 1998; Van Merriënboer \& Sweller, 2005). On the other hand, positive effects of interactivity are only found when the interactivity evokes the right kind of cognitive activities, that is, activities that contribute to understanding (Moreno \& Mayer, 2007). Especially for low prior knowledge learners, the instruction to actively segment may be an additional task that requires cognitive capacity but distracts from learning (i.e., extraneous load; Sweller et al., 1998; cf. Schwan et al., 2000).

In sum, this study investigates whether the effects of segmentation on efficiency of learning found by Spanjers et al. (2011) can be replicated with written worked examples and whether actively segmenting written examples will foster or hamper learning outcomes, invested mental effort, and their combination. The learning outcomes and mental effort were combined by calculating efficiency with the formula developed by Paas and Van Merriënboer (1993). However, in line with the analyses in Spanjers et al., we calculated efficiency with test performance and mental effort invested during studying the examples (i.e., efficiency in terms of learning process, where a high efficiency denotes equal/ low investment of effort during learning combined with high/equal performance on the test) rather than with test performance and mental effort during solving the posttest items (i.e., efficiency in terms of learning outcomes, where a high efficiency denotes equal/low investment of effort during solving the posttest items combined with high/equal performance on the test; see Van Gog \& Paas, 2008).

\section{METHOD}

\section{Participants and design}

Fifty-two Dutch students in their third year of pre-university education (i.e., the highest level of secondary education in the Netherlands with a 6-year duration) participated in this study $(52 \%$ women; mean age 14.62 years, $\mathrm{SD}=0.66)$. They were randomly assigned to one of three conditions: studying nonsegmented worked examples $(n=18)$, studying segmented worked examples $(n=17)$, or actively segmenting worked examples while studying them $(n=17)$.

\section{Materials}

\section{Worked examples}

The four worked examples on probability calculation consisted of written text describing the solution moves to be taken in solving four different types of probability calculation problems. The four types of problems differed on two factors that are important for probability calculation: relevance of order and replacement after drawing. (cf. Opfermann, 2008; Spanjers et al., 2011; Wouters, Paas, \& Van Merriënboer, 2009, 2010). The text of the written examples was the same as the spoken text in the animated worked examples with mountain bike cover stories used by Spanjers et al. (see also Wouters et al., 2009, 2010). To encourage students to focus on relevant (instead of irrelevant) differences between the problem types, a similar cover story (i.e., about helmets distributed on a 2-day mountain bike trip) was used in each worked example. An example of one of the problems presented in the worked examples is: 'Together with your friend, you go on a two-day mountain bike trip. Each day the instructor brings five helmets, which each have a different color: blue, green, yellow, red and silver. The helmets are distributed randomly and are given back to the instructor at the end of the day. On both days you get a helmet first and your friend second. What is the probability that on the first day, you will get the blue helmet and your friend will get the green helmet?'

Two methods for solving probability calculation problems are the method of counting and the method of individual events. The method of counting was demonstrated in the worked examples with a cover story implying that order was relevant. This method consists of determining both the number of possible outcomes and the number of correct outcomes. For example, if one wants to calculate the probability of getting a blue helmet out of five helmets on the first day of a mountain bike trip and a green helmet on the second day, one calculates that there are $5^{2}=25$ possible outcomes and determines that only one of those outcomes is correct. Therefore, the probability is $1 / 25$ that one gets a blue helmet out of 
five helmets on the first day of a mountain bike trip and a green one on the second day. The method of individual events was demonstrated in examples with cover stories implying that order was irrelevant. This method involves determining the probability of each of the individual events involved in the problem and multiplying those probabilities to calculate the probability for the complex event specified in the cover story. For example, if one wants to calculate the probability of obtaining the blue and the green helmet out of five helmets during a 2-day mountain bike trip (regardless of which helmet is obtained on which day), one determines that the probability for the first event is $2 / 5$ and for the second event $1 / 5$. Consequently, the probability of obtaining a blue and a green helmet during a 2-day mountain bike trip is $2 / 5 * 1 / 5=2 / 25$.

In the segmented condition, blank lines were inserted to visually isolate the different segments in the examples. The segments were identical to the segments of four of the animated worked examples used in the study by Spanjers et al. (2011). The first segment presented the cover story including the problem statement, the second segment was about relevance of order, and the third segment about drawing with or without replacement. When the method of counting was demonstrated, the number of possible outcomes was calculated in the fourth segment. In the fifth segment, the probability was determined based on this number of possible outcomes and the number of correct outcomes. When the method of individual events was demonstrated, the probability of the first individual event was determined in the fourth segment and the probability of the second individual event was determined in the fifth segment. In the sixth segment, the probabilities were multiplied to determine the probability for the complex event.

\section{Pretest and posttest}

The pretest and posttest were isomorphic, that is, they contained items with the same structural features but different cover stories. They consisted of four multiple choice items and four open questions on probability calculation (cf. Gerjets, Scheiter, Opfermann, Hesse, \& Eysink, 2009; Opfermann, 2008). An example of a multiple choice item is: 'You have an opaque bag with rummikub stones from which you select 3 stones. You want to get a red seven, orange eight, and black nine in this specific order. Does it matter whether you put back the selected stone before selecting a new stone or not?' The open questions consisted of problems with the same structural features but cover stories that were different from the problems solved in the worked examples. An example of an open question is: 'If you shop for 10 euro at the supermarket, you obtain a key ring for free. It is decided randomly which key ring you will get. You like two of the six key rings. You shop two times for 10 euro. What is the probability that you get both key rings you like?'

\section{Mental effort rating scale}

To measure mental effort invested in studying the examples and in solving the posttest items, the nine-point rating scale developed by Paas (1992) was used, which ranges from (1) very, very low mental effort to (9) very, very high mental effort.

\section{Procedure}

This study was run at the students' school in classroom sessions, with students in each classroom being randomly assigned to one of the three conditions. The students first completed the pretest. Subsequently, they read a one-page introduction containing some information they needed for understanding the examples as well as the instructions concerning their specific condition. The students in the nonsegmented and segmented condition were instructed to study the worked examples, and the students in the actively segmenting condition were instructed to divide the nonsegmented worked examples in minimally three and maximally nine nonoverlapping and consecutive segments by placing markers at the boundaries during studying. After reading the introduction, the participants studied the four worked examples and then completed the posttest. During the pretest and the posttest, the students were allowed to use a calculator and received a page of A4 paper that had the equations needed for solving the problems printed on it (this did not provide students with any clues as to when to use which equation). They were instructed to write out their problem solution for the open questions. Immediately after each example and after each posttest item, the students rated the mental effort they invested in studying that example or solving that item. After the posttest, they were debriefed and thanked for their participation.

\section{Scoring}

The students' answers to the multiple choice items were scored by assigning one point for a correct answer, and their answers to the open questions were scored by assigning one point for use of the correct formula and one point for providing the correct answer. In scoring the formula, both determining the number of possible and correct outcomes and multiplying the probabilities for the individual events involved were considered correct for each open question regardless of the type of problem involved. The maximum score on both the pretest and the posttest was 12 points.

\section{RESULTS}

Means and standard deviations of performance, mental effort, and efficiency data are provided in Table 1. To report the effect sizes of the analyses, $\eta_{p}{ }^{2}$ is used. Values of .01, .06, and .14 are respectively small, moderate, and large effect sizes.

\section{Performance increase}

A repeated measures ANOVA with scores on the pretest and the posttest as within-subjects variables and condition as a between-subjects variable showed a significant increase in scores from the pretest to the posttest, $F(1,49)=12.56$, $p=.001, \eta_{p}^{2}=.204$, so on average, the students in all conditions learned from the examples. However, no significant differences were found between the three conditions, $F(2,49)<1$.

\section{Mental effort}

With regard to mental effort invested during example study, an ANOVA showed significant differences between conditions, $F(2,49)=8.68, p=.001, \eta_{p}^{2}=.262$. Post-hoc analyses 
Table 1. Descriptive statistics for pretest and posttest performance and mental effort during example study and posttest per condition

\begin{tabular}{|c|c|c|c|c|c|c|}
\hline & \multicolumn{2}{|c|}{ Nonsegmented } & \multicolumn{2}{|c|}{ Segmented } & \multicolumn{2}{|c|}{ Actively segmenting } \\
\hline & $M$ & $\mathrm{SD}$ & $M$ & $\mathrm{SD}$ & $M$ & SD \\
\hline Pretest performance $(0-12)$ & 4.11 & 1.41 & 5.06 & 1.64 & 4.18 & 1.51 \\
\hline Posttest performance $(0-12)$ & 5.50 & 2.31 & 6.18 & 2.88 & 5.29 & 2.66 \\
\hline Mental effort during example study (1-9) & 4.33 & 1.85 & 3.22 & 1.59 & 5.67 & 1.69 \\
\hline Mental effort during the posttest (1-9) & 4.08 & 1.71 & 3.62 & 1.81 & 4.93 & 1.42 \\
\hline Efficiency & -0.02 & 0.96 & 0.57 & 1.15 & -0.55 & 0.98 \\
\hline
\end{tabular}

showed that in line with our hypothesis, the students in the actively segmenting condition invested significantly more mental effort in studying the examples than the students in the nonsegmented condition $(p=.03)$ and the segmented condition $(p=.00)$. Also in line with our expectation, the students in the segmented condition invested less mental effort in studying the examples than the students in the nonsegmented condition, although this effect was only marginally significant $(p=.06)$.

Additionally, marginally significant differences were found with regard to mental effort invested in the posttest, $F(2,49)=2.73, p=.08, \eta_{p}^{2}=.100$. Post-hoc analyses showed that the students in the actively segmenting condition invested more mental effort in solving the posttest items than the students in the segmented condition $(p=.03)$.

\section{Efficiency}

Furthermore, the conditions differed significantly with regard to efficiency, $F(2,49)=5.05, p=.01, \eta_{p}^{2}=.171$. In line with the previous findings, learning was found to be more efficient for the students in the segmented worked examples condition than in the actively segmenting condition $(p=.003)$. Additionally, a marginally significant difference in favor of the segmented condition was found when compared with the nonsegmented condition $(p=.10)$.

\section{DISCUSSION}

This study had two aims. First, it was to investigate whether the cueing explanation for the effectiveness of segmentation (see Spanjers et al., 2010) may explain why studying segmented animated worked examples leads to equal learning outcomes with less mental effort than studying continuous examples, as found by Spanjers et al. (2011). To study this, we used segmented and nonsegmented written examples with the same text as the animated examples of Spanjers et al. The previous findings were replicated: studying worked examples in a segmented format decreased the mental effort required during learning without lowering performance on the test administered after study. This suggests that learning from segmented worked examples is more efficient than learning from nonsegmented examples, and indeed, a marginally significant difference was found on the measure of efficiency. It provides further evidence that segmenting is not only effective for animated materials but also for static written learning materials (Catrambone, 1995; Florax \& Ploetzner, 2010). Though it is possible that learners paused shortly at the end of each segment, the examples were not transient and they could have paused at any time, making it unlikely that the pausing explanation (i.e., giving the learners additional time to perform necessary cognitive processes) can completely explain the findings. The positive effects of segmentation on mental effort seem to lend support to the cueing explanation, that is, the segments help learners to group information elements that belong together.

However, it should be noted that this does not necessarily imply that the pauses typically used in segmenting dynamic visualizations play no role at all in explaining the beneficial effects of segmentation. First of all, the two explanations for the effectiveness of segmentation in dynamic visualizations are not mutually exclusive (Spanjers et al., 2010), and-as mentioned previously-we cannot rule out that the learners paused shortly when they came across the blank lines in the segmented examples in this study. The current study only found evidence for the cueing explanation of the segmentation effect, but future research should further disentangle the cognitive processes involved in cueing and pausing. To test their plausibility, the effects of inserting pauses in dynamic visualizations could be compared with the effects of inserting other cues, which segment the dynamic visualizations without providing learners with additional time for processing. Alternatively, the plausibility of the two processes can be investigated by comparing the effects of pauses segmenting dynamic visualizations in meaningful segments with the effects of pauses segmenting them in random segments.

The second aim of this study was to investigate whether increased interactivity by instructing students to actively segment examples during study would hamper or enhance efficiency of learning. The results showed that active segmenting increased the mental effort invested in example study without positively influencing performance. Furthermore, students studying worked examples in a segmented format had to invest less mental effort during the posttest to achieve the same level of test performance than students who were instructed to actively segment the examples while studying them. The students studying worked examples in a segmented format, therefore, had a more efficient learning process than the students who were instructed to actively segment the examples while studying them. Thus, the results of this study suggest that actively segmenting as a form of interactivity is not efficient, at least for low prior knowledge learners such as the students in this study. In a way, this is not surprising: the students in the actively segmenting condition not only had to study the worked examples, just as the students in the other conditions, but they also had to indicate the end of segments. These two processes may have competed for cognitive resources, which may have had a negative effect on the process of learning from the worked examples (cf. Schwan et al., 2000). So, it 
appeared that actively segmenting was an additional task hindering learning by imposing extraneous cognitive load rather than a form of interactivity imposing germane cognitive load.

The finding that actively interacting with the instructional material does not improve learning compared with being provided with manipulated material is in agreement with the findings of Schwamborn, Thillmann, Opfermann, and Leutner (2011). They found that presenting text and pictures was associated with the investment of less mental effort and the need to generate pictures with the investment of more mental effort. Additionally, they found more positive effects on learning outcomes from providing pictures than from having them generated by the learners.

With these studies, it can be concluded that interacting with learning material does not always positively affect learning, at least for low prior knowledge learners. Some factors influencing the effects of interactivity are mentioned in the literature. As shown by this study and also the study of Schwamborn et al. (2011), interacting with learning materials may increase the cognitive load imposed on the learner. To find positive effects on learning outcomes, the learner should not be cognitively overloaded in interactive learning environments (Moreno \& Mayer, 2007). Additionally, to find positive effects of interactivity, it should not only lead to behavioral activity but should also stimulate learners to process the instructional materials more deeply (Moreno \& Mayer, 2007; Wouters, Tabbers, \& Paas, 2007). Moreover, this deep processing should be focused on the core of the learning material and not on other parts of the learning material (Atkinson \& Renkl, 2007). With a review of studies investigating the effects of generating pictures during studying text, Schwamborn et al. argued that students need to be supported to profit from generation activities. A similar idea is proposed by Moreno and Mayer (2007), who stated that guided interactivity in which students interact with a pedagogical agent who prompts them to actively engage in processing the material is better than unguided discovery learning. The given support or guidance should optimize the cognitive load provided by the interactivity or in other words, should decrease extraneous cognitive load to avoid cognitive overload and should increase germane cognitive load imposed by deeper processing of the core of the learning material (Moreno \& Mayer, 2007; Schwamborn et al., 2011; Van Merriënboer \& Kirschner, 2007). Future research should examine for other types of interactivity whether they are effective and which types of support are needed with those types of interactivity to be effective.

Another interesting topic for future research is the influence of prior knowledge on the effects of segmentation. Spanjers et al. (2011) found that segmented animated worked examples were more efficient than continuous ones for students with lower levels of prior knowledge but not for students with higher levels of prior knowledge. This suggests that once students have sufficient prior knowledge, segmentation does no longer have a positive effect on efficiency. Research on the expertise reversal effect has indeed shown that once students have acquired some knowledge of a task, they become less dependent on instructional guidance and such guidance might sometimes even hamper learning (Kalyuga, 2007; Kalyuga et al., 2003). However, it may be that once learners have acquired more knowledge, active segmenting becomes more effective. Because the load imposed by the learning task is lower for advanced learners (see Sweller et al., 1998), they may have the cognitive capacity available to engage in actively segmenting and to learn from interacting in this way with the instructional materials. Future research could examine whether an expertise reversal effect also occurs with actively segmenting instructional material.

In conclusion, this study contributes to our knowledge of effects of different example design and delivery techniques, by showing that presenting learners with worked examples in a segmented format increases the efficiency of the process of learning, whereas instructing them to actively segment examples decreases the efficiency of their learning process. Designers of instructional material for low prior knowledge learners could take these findings into account by presenting worked examples in a segmented format. Furthermore, they should not include interactivity consisting of asking students to actively segment worked examples themselves.

\section{ACKNOWLEDGEMENT}

This work was funded by the Netherlands Organization for Scientific Research (NWO; project no. 400-07-017).

\section{REFERENCES}

Atkinson, R. K., Derry, S. J., Renkl, A., \& Wortham, D. (2000). Learning from examples: Instructional principles from the worked examples research. Review of Educational Research, 70, 181-214.

Atkinson, R. K., \& Renkl, A. (2007). Using interactive example-based learning environments: Using interactive elements to encourage effective processing of worked examples. Educational Psychology Review, 19, 375-386.

Atkinson, R. K., Renkl, A., \& Merrill, M. M. (2003). Transitioning from studying examples to solving problems: Effects of self-explanation prompts and fading worked-out steps. Journal of Educational Psychology, 95, 774-783.

Ayres, P., \& Paas, F. (2007a). Making instructional animations more effective: A cognitive load approach. Applied Cognitive Psychology, 21, 695-700.

Ayres, P., \& Paas, F. (2007b). Can the cognitive load approach make instructional animations more effective? Applied Cognitive Psychology, 21, 811-820.

Catrambone, R. (1995). Aiding subgoal learning: Effects on transfer. Journal of Educational Psychology, 87, 5-17.

Catrambone, R. (1996). Generalizing solution procedures learned from examples. Journal of Experimental Psychology. Learning, Memory, and Cognition, 22, 1020-1031.

Catrambone, R. (1998). The subgoal learning model: Creating better examples so that students can solve novel problems. Journal of Experimental Psychology. General, 127, 335-376.

Chandler, P., \& Sweller, J. (1991). Cognitive load theory and the format of instruction. Cognition and Instruction, 8, 293-332.

Cooper, G., \& Sweller, J. (1987). Effects of schema acquisition and rule automation on mathematical problem-solving transfer. Journal of Educational Psychology, 79, 347-362.

Florax, M., \& Ploetzner, R. (2010). What contributes to the split-attention effect? The role of text segmentation, picture labeling, and spatial proximity. Learning and Instruction, 20, 216-224.

Gerjets, P., Scheiter, K., Opfermann, M., Hesse, F. W., \& Eysink, T. H. S. (2009). Learning with hypermedia: The influence of representational formats and different levels of learner control on performance and learning behavior. Computers in Human Behavior, 25, 360-370. 
Hasler, B. S., Kersten, B., \& Sweller, J. (2007). Learner control, cognitive load and instructional animation. Applied Cognitive Psychology, 21, 713-729.

Hoffman, B., \& Schraw, G. (2010). Conceptions of efficiency: Applications in learning and problem solving. Educational Psychologist, 45, 1-14.

Kalyuga, S. (2007). Expertise reversal effect and its implications for learnertailored instruction. Educational Psychology Review, 19, 509-539.

Kalyuga, S., Ayres, P., Chandler, P., \& Sweller, J. (2003). The expertise reversal effect. Educational Psychologist, 38, 23-31.

Kalyuga, S., Chandler, P., Tuovinen, J., \& Sweller, J. (2001). When problem solving is superior to studying worked examples. Journal of Educational Psychology, 93, 579-588.

Kurby, C. A., \& Zacks, J. M. (2008). Segmentation in the perception and memory of events. Trends in Cognitive Sciences, 12, 72-79.

Leahy, W., \& Sweller, J. (2011). Cognitive load theory, modality of presentation and the transient information effect. Applied Cognitive Psychology. Advance online publication. doi: 10.1002/acp.1787

Lovett, M. C. (1992). Learning by problem solving versus by examples: The benefits of generating and receiving information. In Proceedings of the 14th Annual Conference of the Cognitive Science Society (pp. 956-961). Hillsdale, NJ: Erlbaum.

Lowe, R. K. (1999). Extracting information from an animation during complex visual learning. European Journal of Psychology of Education, 14, 225-244.

Mayer, R. E., \& Chandler, P. (2001). When learning is just a click away: Does simple user interaction foster deeper understanding of multimedia messages? Journal of Educational Psychology, 93, 390-397.

Mayer, R. E., \& Moreno, R. (2003). Nine ways to reduce cognitive load in multimedia learning. Educational Psychologist, 38, 43-52.

McLaren, B. M., Lim, S., \& Koedinger, K. R. (2008). When and how often should worked examples be given to students? New results and a summary of the current state of research. In B. C. Love, K. McRae, \& V. M. Sloutsky (Eds.), Proceedings of the 30th Annual Conference of the Cognitive Science Society (pp. 2176-2181). Austin, TX: Cognitive Science Society.

Moreno, R. (2007). Optimising learning from animations by minimising cognitive load: Cognitive and affective consequences of signalling and segmentation methods. Applied Cognitive Psychology, 21, 765-781.

Moreno, R., \& Mayer, R. (2007). Interactive multimodal learning environments. Educational Psychology Review, 19, 309-326.

Opfermann, M. (2008). There's more to it than instructional design: The role of individual learner characteristics for hypermedia learning. Berlin: Logos.

Paas, F. (1992). Training strategies for attaining transfer of problem-solving skill in statistics: A cognitive-load approach. Journal of Educational Psychology, 84, 429-434.

Paas, F., \& Van Gog, T. (2006). Optimising worked example instruction: Different ways to increase germane cognitive load. Learning and Instruction, 16, 87-91.

Paas, F., \& Van Merriënboer, J. J. G. (1993). The efficiency of instructional conditions: An approach to combine mental effort and performance measures. Human Factors, 35, 737-743.

Paas, F., \& Van Merriënboer, J. J. G. (1994). Variability of worked examples and transfer of geometrical problem-solving skills: A cognitive-load approach. Journal of Educational Psychology, 86, 122-133.

Schwamborn, A., Thillmann, H., Opfermann, M., \& Leutner, D. (2011). Cognitive load and instructionally supported learning with provided and learnergenerated visualizations. Computers in Human Behavior, 27, 89-93.

Schwan, S., Garsoffky, B., \& Hesse, F. W. (2000). Do film cuts facilitate the perceptual and cognitive organization of activity sequences? Memory \& Cognition, 28, 214-223.

Schwonke, R., Renkl, A., Krieg, C., Wittwer, J., Aleven, V., \& Salden, R. (2009). The worked-example effect: Not an artefact of lousy control conditions. Computers in Human Behavior, 25, 258-266.
Spanjers, I. A. E., Van Gog, T., \& Van Merriënboer, J. J. G. (2010). A theoretical analysis of how segmentation of dynamic visualizations optimizes students' learning. Educational Psychology Review.

Spanjers, I. A. E., Wouters, P., Van Gog, T., \& Van Merriënboer, J. J. G. (2011). An expertise reversal effect of segmentation in learning from animations. Computers in Human Behavior, 27, 46-52.

Sweller, J. (1988). Cognitive load during problem solving: Effects on learning. Cognitive Science, 12, 2567-285.

Sweller, J. (2006). The worked example effect and human cognition. Learning and Instruction, 16, 165-169.

Sweller, J., \& Cooper, G. A. (1985). The use of worked examples as a substitute for problem solving in learning algebra. Cognition and Instruction, 2, 59-89.

Sweller, J., Van Merriënboer, J. J. G., \& Paas, F. (1998). Cognitive architecture and instructional design. Educational Psychology Review, 10, 251-296.

Tarmizi, R., \& Sweller, J. (1988). Guidance during mathematical problem solving. Journal of Educational Psychology, 80, 424-436.

Van Gog, T., \& Paas, F. (2008). Instructional efficiency: Revisiting the original construct in educational research. Educational Psychologist, 43, 16-26.

Van Gog, T., Paas, F., \& Van Merriënboer, J. J. G. (2006). Effects of process-oriented worked examples on troubleshooting transfer performance. Learning and Instruction, 16, 154-164.

Van Gog, T., Paas, F., \& Van Merriënboer, J. J. G. (2008). Effects of studying sequences of process-oriented and product-oriented worked examples on troubleshooting transfer efficiency. Learning and Instruction, 18, 211-222.

Van Gog, T., \& Rummel, N. (2010). Example-based learning: Integrating cognitive and social-cognitive research perspectives. Educational Psychology Review, 22, 155-174.

Van Merriënboer, J. J. G. (1990). Strategies for programming instruction in high school: Program completion vs. program generation. Journal of Educational Computing Research, 6, 265-285.

Van Merriënboer, J. J. G., \& De Croock, M. B. M. (1992). Strategies for computer-based programming instruction: Program completion vs. program generation. Journal of Educational Computing Research, 8, 365-394.

Van Merriënboer, J. J. G., \& Kirschner, P. A. (2007). Ten steps to complex learning: A systematic approach to four-component instructional design. Mahwah, NJ: Erlbaum/Taylor and Francis.

Van Merriënboer, J. J. G., \& Sweller, J. (2005). Cognitive load theory and complex learning: Recent developments and future directions. Educational Psychology Review, 17, 147-177.

Wouters, P., Paas, F., \& Van Merriënboer, J. J. G. (2008). How to optimize learning from animated models: A review of guidelines based on cognitive load. Review of Educational Research, 78, 645-675.

Wouters, P., Paas, F., \& Van Merriënboer, J. J. G. (2009). Observational learning from animated models: Effects of modality and reflection on transfer. Contemporary Educational Psychology, 34, 1-8.

Wouters, P., Paas, F., \& Van Merriënboer, J. J. G. (2010). Observational learning from animated models: Effects of studying-practicing alternation and illusion of control on transfer. Instructional Science, 38, 89-104.

Wouters, P., Tabbers, H. K., \& Paas, F. (2007). Interactivity in video-based models. Educational Psychology Review, 19, 327-342.

Zacks, J. M., Speer, N. K., Reynolds, J. R. (2009). Segmentation in reading and film comprehension. Journal of Experimental Psychology. General, 13, 307-327.

Zacks, J. M., Speer, N. K., Swallow, K. M., Braver, T. S., \& Reynolds, J. R. (2007). Event perception: A mind-brain perspective. Psychological Bulletin, 133, 273-293.

Zhu, X., \& Simon, H. A. (1987). Learning mathematics from examples and by doing. Cognition and Instruction, 4, 137-166. 